\title{
UM ENSAIO BIOGRÁFICO: MEMÓRIAS DO PROFESSOR SVEN ROBERT SCHULZE
}

\author{
A BIOGRAPHICAL ESSAY: MEMOIRS OF PROFESSOR SVEN ROBERT SCHULZE
}

UN ENSAYO BIOGRÁFICO: MEMORIAS DEL PROFESOR SVEN ROBERT SCHULZE

\author{
HASS DA SILVA, Eduardo Cristiano ${ }^{1}$ \\ DUARTE, Ariane dos Reis² \\ GRAZZIOTIN, Lucane Sgarbi Santos ${ }^{3}$
}

\section{RESUMO}

O artigo tem por objetivo analisar nuances da vida de Sven Robert Schulze, indivíduo que esteve à frente da fundação, gestão e docência da Escola Técnica de Comércio (ETC) do Colégio Farroupilha de Porto Alegre/RS (1950-1983). Utilizam-se as teorias e conceitos da História Cultural, sobretudo no que diz respeito ao gênero biográfico em articulação com a História da Educação. A investigação recorre a materiais empíricos diversos (documentos escritos, fotografias e narrativas de memória). Identificam-se elementos da vida do indivíduo biografado como contador, empresário, conselheiro, professor, pai e, em especial, como idealizador e organizador da ETC Farroupilha. Os apontamentos finais demonstram como esse ensaio biográfico contribu, para uma reflexão sobre a História da Educação Brasileira, no que diz respeito a participação do indivíduo e suas singularidades nesse contexto.

Palavras-chave: Sven Robert Schulze. Biografia Histórica. História da Educação

\section{ABSTRACT}

The article aims to analyze the nuances of the Sven Robert Schulze's life, an individual who was the head of the foundation, management and teaching of the Escola Técnica de Comércio (ETC) do Colégio Farroupilha de Porto Alegre/RS (1950-1983). Theories and concepts of Cultural History are used, especially with regard to the biographical genre in articulation with the History of Education. The research uses diverse empirical materials (written documents, photographs and memory narratives). Identifying elements of the life of the biographical individual as accountant, entrepreneur, counselor, teacher, father and, in particular, as founder and organizer of ETC Farroupilha. The final notes show how this biographical text can contribute to a reflection on the History of Brazilian Education, regarding the participation of the individual and its singularities in this context.

Keywords: Sven Robert Schulze. Historical Biography. History of Education

\section{RESUMEN}

El artículo tiene por objetivo analizar los matices de la vida de Sven Robert Schulze, individuo que estuvo al frente de la fundación, gestión y docencia de la Escuela Técnica de Comercio (ETC) del Colegio Farroupilha de Porto Alegre / RS (19501983). Se utilizan las teorías y conceptos de la Historia Cultural, sobre todo en lo que se refiere al género biográfico en articulación con la Historia de la Educación. La investigación recurre a materiales empíricos diversos (documentos escritos, fotografías y narrativas de memoria). Se identifican elementos de la vida del individuo biografiado como contador, empresario, consejero, profesor, padre y, en especial, como idealizador y organizador de la ETC Farroupilha. Los apuntes finales demuestran como ese ensayo biográfico contribuyó, para una reflexión sobre la Historia de la Educación Brasileña, en lo que se refiere a la participación del individuo y sus singularidades en ese contexto

Palabras clave: Sven Robert Schulze. Biografía Histórica. Historia de la Educación

\section{INTRODUÇÃO}

\footnotetext{
1 Universidade do Vale do Rio dos Sinos - UNISINOS - São Leopoldo - Rio Grande do Sul - Brasil

2 Universidade do Vale do Rio dos Sinos - UNISINOS - São Leopoldo - Rio Grande do Sul - Brasil

3 Universidade do Vale do Rio dos Sinos - UNISINOS - São Leopoldo - Rio Grande do Sul - Brasil
} 
O presente estudo consiste em um recorte da pesquisa realizada dentro do projeto "Entre Memórias e Histórias da Escola no Rio Grande do Sul: do Deutscher Hilfsverein ao Colégio Farroupilha (1858-2008)", que resultou na dissertação intitulada "A Gênese de um Espaço Profissional: A Escola Técnica de Comércio do Colégio Farroupilha de Porto Alegre/RS (1950-1983)". A partir dos documentos produzidos na dissertação e no percurso das investigações desenvolvidas no âmbito do grupo de pesquisa ${ }^{4}$ que integramos, esta produção mobiliza elementos de nossas pesquisas individuais, de modo a combinar perspectivas teóricas trabalhadas por seus autores.

Assim, o artigo tem como objeto de análise a vida de Sven Robert Schulze ${ }^{5}$ nos distintos aspectos que, por meio de documentos orais, visuais e escritos, conseguimos compor o que denominamos nesse estudo de nuances. A trajetória profissional de Schulze está fortemente vinculada à Escola Técnica de Comércio (ETC) do Colégio Farroupilha de Porto Alegre, instituição privada que ofereceu o Curso Técnico de Contabilidade entre os anos de 1950 e 1983. O referido personagem esteve à frente da fundação, gestão e docência deste curso. Desse modo, o texto analisa as memórias e representações sobre o professor a partir das dimensões que compõe seu percurso.

Considerando o objetivo proposto, o trabalho utiliza-se das teorias e conceitos vinculados a História Cultural (CHARTIER, 1990), sobretudo no que diz respeito ao gênero biográfico (DOSSE, 2012) que, por meio de suas renovações, vem consolidando-se. Nesse sentido o referido gênero "[...] está à altura de abrir portas ao conjunto das ciências humanas e literárias graças a sua receptividade. Tornam-se possíveis a prática de estudos transversais e o diálogo entre universos de interpretação diferentes" (2015, p.17).

A partir desta colocação entendemos que este texto, produzido no âmbito da História da Educação, em alguma medida contribui para uma aproximação com os estudos que tem a vida de um determinado indivíduo como objeto. Assim, tais pesquisas contribuem para que sejam observadas as singularidades dos processos históricos no âmbito da educação, bem como para discutir o papel desenvolvido pelos indivíduos nestes contextos.

O percurso metodológico apresentado a seguir está diretamente ligado à História Cultural, portanto recorre a materiais empíricos diversos como documentos escritos, fotografias e narrativas de memória que, em articulação com o referencial teórico, possibilitam tratar de determinadas dimensões da vida de um homem que se tornou professor e idealizador uma instituição educativa.

\section{HISTÓRIA DA EDUCAÇÃO E BIOGRAFIA HISTÓRICA: UM DIÁLOGO POSSÍVEL}

\footnotetext{
${ }^{4}$ Grupo de pesquisa EBRAMIC: Educação no Brasil: memórias, instituições e cultura escolar.

5 Percebeu-se a variação na grafia do nome do professor em diferentes documentos. As grafias encontradas foram Sven Robert Schulze, Sven Roberto Schulze e Swen Robert Schulze. Adotou-se a primeira grafia como padrão, uma vez que é a que mais aparece.
} 
De acordo com a pesquisadora e professora Maria Helena Bastos (2016), o conceito de História da Educação pode ser compreendido a partir de duas perspectivas: como uma disciplina de formação e um campo de pesquisa. Enquanto disciplina de formação, a autora salienta que a História da Educação está diretamente ligada a disciplinas ministradas na Escola Normal. Apesar de os cursos normais terem surgido em 1835 e se expandido no século XX, a autora destaca que poucas escolas ofereciam a disciplina de História da Pedagogia. É a partir da Lei Orgânica do Ensino Normal, de 1946, que a disciplina passa a ser obrigatória. Em nível superior, o curso de pedagogia é criado em 1939 e também inclui na grade curricular a disciplina de História e Filosofia da Educação.

Enquanto campo de pesquisa, Stephanou e Bastos (2005) entendem a História da Educação como uma área fronteiriça, cuja riqueza teórica e metodológica está justamente no espaço em que ocupa entre a História e a Educação. Considerando este espaço interdisciplinar no qual a História da Educação se encontra, o pesquisador que a utiliza como campo pode empregar conceitos e métodos tanto da História quanto da Educação. Além das vastas possibilidades teórico-metodológicas, a História da Educação conta com um número significativo de temas de investigação, dentre eles:

\footnotetext{
[...] a história do ensino, a história do livro e da leitura, a história dos manuais didáticos, a história da criança, a história da educação das mulheres, a história da adolescência ou dos jovens; a história dos impressos de educação e de ensino; a história das instituições de ensino; a história das ideias pedagógicas; a história dos sistemas escolares; a história das disciplinas escolares; história da Universidade, história das práticas educativas não-escolares, história do currículo, dentre muitos outros (STEPHANOU; BASTOS, 2005. p. 427).
}

Como podemos observar, o rol de temas apresentados pelas autoras é significativamente vasto. Dentre as possibilidades apresentadas, para este estudo, damos principal atenção a um tema não mencionado pelas autoras, mas potente para a área: a vida de professores, neste caso a trajetória de Sven Robert Schulze, professor cujo percurso está diretamente relacionada a ETC Farroupilha.

Dito isso, é importante frisar que os estudos de cunho biográfico não têm intenção de estabelecer uma narrativa definitiva para a vida do personagem abordado. Neste caso, de posse do acervo constituído e analisado, estabelecemos dimensões possíveis para a existência do personagem em questão. Isso porque a premissa básica deste tipo de estudo é ter em vista a pluralidade de significados de uma vida.

Assim, o historiador biógrafo não define a priori o que quer saber e abordar sobre o biografado, "que não está de modo algum imobilizado numa estrutura atemporal de partida na qual já se desenhasse o itinerário ulterior" (DOSSE, 2015, p. 376). Ou seja, o percurso de pesquisa desenvolvido requer o cuidado de não traçar a narrativa de vida preso aos desfechos dessa existência. Como demonstraremos ao longo deste trabalho, o indivíduo aqui investigado ocupa diferentes lugares na Escola de Comércio, sendo professor, administrador e também pai de alunos, o que mostra o potencial da pesquisa histórica relacionada ao personagem elencado.

De acordo com Alexandre Avelar (2010), a biografia ${ }^{6}$ pode ser compreendida dentre de um processo ocorrido nas últimas décadas, no qual a historiografia tem experimentado alguns retornos,

\footnotetext{
${ }^{6}$ Uma perspectiva histórica do gênero biográfico é apresentada por Mary Del Priore em 'Biografia: quando o indivíduo encontra a história' (2009). A autora retoma como o gênero se constituiu na antiguidade com os trabalhos de Heródoto e Tucídides na
}

Reflexão e Ação [ISSN 1982-9949]. Santa Cruz do Sul, v. 27, n. 3, p. 109-127, set./dez. 2019.https://online.unisc.br/seer/index.php/reflex/index 
como o retorno à narrativa, ao acontecimento e à história política. Segundo o autor, são retornos que, a partir da História dos Annales ${ }^{7}$, estavam relegados a segundo plano, uma vez que está corrente historiográfica favoreceu a noção de estrutura. O autor evidencia que a partir dos anos 1960 a biografia suscita preocupações, já indicadas por Roger Chartier (1994) que ressalva a virada epistemológica em direção ao indivíduo:

O objeto da história, portanto, não são, ou não são mais, as estruturas e os mecanismos que regulam, fora de qualquer controle subjetivo, as relações sociais, e sim as racionalidades e as estratégias acionadas pelas comunidades: as parentelas, as famílias e os indivíduos (CHARTIER, 1994, p. 98 apud AVELAR, 2010).

Considerando a importância dos estudos sobre as parentelas, famílias e indivíduos, estes temas passam a ser gradativamente incorporados ao modelo dos Annales. Para Loriga (2011), no esforço de legitimar os estudos históricos como pesquisas científicas de cunho mais objetivo, o indivíduo e suas dimensões foram relegados a segundo plano.

Sobre a construção de uma biografia, Avelar (2010) destaca a importância de compreender que a narrativa histórica produzida pelo historiador é a mais próxima da verdade, permitindo afirmar que "este percurso não é estranho à elaboração de uma biografia e o historiador-biógrafo não pode renunciar à tarefa de narrar uma história verdadeira a partir da observação de certos cânones constituintes da pesquisa histórica" (AVELAR, 2010. p. 161). Ou seja, embora se debruce sobre um objeto multidimensional - uma vida - a biografia histórica ${ }^{8}$ como a entendemos, segue os preceitos e rigor dos demais estudos historiográficos.

Propomos então apresentar uma narrativa possível sobre a trajetória de Sven Robert Schulze, tendo noção de que outras narrativas seriam possíveis de acordo com as fontes obtidas e acervo produzido. Desse modo o conteúdo aqui apresentado corresponde a algumas dimensões dessa existência, uma vez que outros elementos dessa vida não podem ser acessados a partir da documentação produzida.

\section{BIOGRAFANDO: DA COMPOSIÇÃO E TRATO DO ACERVO}

Grécia Antiga e de Tito Lívio e Tácito na Roma Antiga. Em seguida, destaca como a biografia é utilizada no início da Idade Média para o registro da vida dos santos (hagiografia) e no final do mesmo período para as vidas dos cavaleiros, configurados como heróis. No Renascimento, a biografia está ligada ao culto de si, que torna-se meta de todas as coisas. Indo além, a autora destaca que no século XVIII o herói medieval é substituído pelos grandes homens e, no XIX, as biografias tem importante papel na construção da ideia de nação, imortalizando heróis e monarcas.

${ }^{7}$ A Escola dos Annales surge com a criação da revista Annales d'Histoire Économique et Sociale, fundada por Lucien Febvre e March Bloch e inaugura um processo de renovação na historiografia, onde outros temas e abordagens passam a compor o campo da história. A partir do movimento dos Annales forma-se a chamada História Cultural.

8 O termo remete aos estudos biográficos desenvolvidos por Jacques Le Goff, que, sobretudo ao final da década de 1980, contribuem para uma renovação no âmbito do gênero biográfico. O conceito em questão e a perspectiva biográfica aparecem em obras como São Luís - Biografia (1996) e São Francisco de Assis (2001). 
De acordo com Avelar (2010), a biografia histórica pode ser entendida como uma modalidade de escrita da História que é profundamente imbricada em subjetividades, afetos, modos de ver, perceber e sentir o outro. Dessa forma, visando manter o rigor científico do seu trabalho, cabe ao historiadorbiógrafo explicitar para o leitor o método empregado, explicando suas razões de escolha do personagem biografado, as fontes e conceitos utilizados, bem como as perguntas que serão feitas.

Como evidenciamos no início deste texto, a escolha pelo indivíduo biografado não é neutra, e se dá a partir de um trabalho anterior, desse modo, Eduardo Cristiano Hass da Silva (2017) analisou a história e trajetória da Escola Técnica de Comércio do Colégio Farroupilha, entre os anos de 1950 e 1983. Ao longo da pesquisa, o autor identificou a importância do professor Schulze como idealizador, docente e diretor da escola, não dedicou, porém, maior atenção sobre sua vida.

Quanto às fontes utilizadas na construção da biografia aqui apresentada, elas são diversas e, a partir da forma de acesso, podem ser classificadas em três grandes grupos: Acervo do Memorial do Colégio Farroupilha de Porto Alegre/RS ${ }^{9}$, Entrevistas de História Oral e Documentos Diversos.

O Colégio Farroupilha de Porto Alegre/RS e sua mantenedora são instituições centenárias. Seu memorial comporta diferentes fases da educação no estado do Rio Grande do Sul e de diferentes momentos da história da Escola. Por meio de seus documentos é possível acessar as práticas cotidianas e uma cultura escolar, singulares aquele espaço ou comuns às instituições de ensino de uma época e/ou região.

Tratando-se dos documentos referentes à Escola Técnica de Comércio do Colégio Farroupilha, o acervo é composto por um total de 10 caixas arquivo (ETC - CX), 12 pastas (ETC - PAS), 3 caixas de fotografias e envelopes com periódicos e convites de formatura.

As caixas arquivo contém termos de expedição de diploma, livros de Inscrição por ordem alfabética de alunos matriculados, certificados de conclusão, diplomas, fichas individuais, tabelas de anuidade escolar, relatórios escolares, avaliações de alunos, Planos Político Pedagógicos (PPPs), Documentos Pessoais de Professores, pareceres, Termos de investidura, Livros de atas de reuniões, entre outros. As pastas do acervo são compostas pelo Relatório de Verificação Prévia da ETC, relatórios escolares em geral, documentos de formatura, correspondências e periódicos.

Destes documentos foram utilizados, para essa pesquisa, relatórios, atas, impressos escolares, fotografias, entre outros. As fotografias foram entendidas e analisadas a partir de Mauad (1996), que destaca que padrões culturais, técnicas fotográficas, intenção do fotógrafo, manipulação da imagem em laboratório ou até a interpretação da imagem fotografada pelo observador são algumas variáveis que influenciam na mensagem a ser transmitida pela fotografia e questionam seu caráter de objetividade. Também não se pode esquecer que o retrato é uma escolha realizada a partir de

\footnotetext{
${ }^{9}$ O Memorial "Deutscher Hilfsverein ao Colégio Farroupilha", é um espaço memorialístico inaugurado em 5 de julho de 2002. De acordo com Jacques e Grimaldi (2013), o espaço surgiu da necessidade de preservar e divulgar a história da escola e de sua mantenedora. Desde sua criação, o memorial guarda diversos documentos, como atas de reuniões, livros de correspondência, periódicos escolares, fotos, mobília, entrevistas de história oral, entre outros. O memorial consiste em um espaço pedagógico, de memória e pesquisa.
}

Reflexão e Ação [ISSN 1982-9949]. Santa Cruz do Sul, v. 27, n. 3, p. 109-127, set./dez. 2019.https://online.unisc.br/seer/index.php/reflex/index 
convenções e dentro de um conjunto de escolhas possíveis, que são determinadas a partir do contexto histórico em que a fotografia foi feita.

O segundo grupo de documentos é composto pelas memórias produzidas com a metodologia de História Oral. As memórias são tomadas como documentos, sem hierarquização em relação às fontes escritas e abordadas em complementaridade com elas. Além disso, memória e história são tratadas como coisas diferentes, sendo para Grazziotin e Almeida (2012, p. 28) um desafio para o historiador "trabalhar com a memória sem a pretensão da verdade com clareza de que ela não é a história, mas que nutre a pesquisa, produzindo uma história". Segundo Paul Ricoeur (2007), assim como a história, na visão de March Bloch, é uma ciência de rastros, assim a memória também pode ser pensada como rastro, formada pela relação entre lembranças e esquecimentos. Dessa maneira, as memórias dos sujeitos entrevistados não são entendidas como história, mas passam pelas três fases da operação historiográfica apresentadas por Ricoeur (2007): fase documental (da declaração das testemunhas oculares à constituição dos arquivos), fase explicativa/compreensiva (questionamento dos documentos produzidos) e fase representativa (colocação em forma literária ou escrita do discurso).

As entrevistas realizadas foram semi estruturadas e, na articulação com demais documentos, permitem compreender parte da trajetória do indivíduo investigado. É importante salientar que todos os entrevistados assinaram "Termo de Consentimento Livre e Esclarecido", autorizando a divulgação dos seus dados, bem como de suas memórias. Os nomes serão utilizados na íntegra devido ao caráter da pesquisa, que analisa trajetórias de sujeitos específicos. $O$ quadro a seguir mostra as principais informações das entrevistas e entrevistados:

\section{Quadro 1: RELAÇÃO DE ENTREVISTADOS}

\begin{tabular}{|l|l|l|l|l|l|}
\hline Nome & $\begin{array}{l}\text { Relação com } \\
\text { o biografado }\end{array}$ & $\begin{array}{l}\text { Data da } \\
\text { entrevista }\end{array}$ & Local da entrevista & Tempo & Páginas \\
\hline $\begin{array}{l}\text { SILLE, Hans } \\
\text { Joachim } \\
\text { Walter }\end{array}$ & $\begin{array}{l}\text { Ex-professor } \\
\text { da ETC }\end{array}$ & $11 / 12 / 2015$ & $\begin{array}{l}\text { Casa do entrevistado. } \\
\text { Porto Alegre/RS. }\end{array}$ & $\begin{array}{l}2 \mathrm{~h} 34 \mathrm{~min} \\
22 \mathrm{~s}\end{array}$ & 44 \\
\hline KLEY, Ivam & $\begin{array}{l}\text { Filho de ex- } \\
\text { professor } \\
\text { (Walter Kley) }\end{array}$ & $28 / 01 / 2016$ & $\begin{array}{l}\text { Memorial do Colégio } \\
\text { Farroupilha. }\end{array}$ & $\begin{array}{l}1 \mathrm{~h} \mathrm{16min} \\
50 \mathrm{~s}\end{array}$ & 41 \\
\hline $\begin{array}{l}\text { SCHULTZ, } \\
\text { Ingrid }\end{array}$ & $\begin{array}{l}\text { Filha de } \\
\text { Sven Schultz }\end{array}$ & $29 / 01 / 2016$ & $\begin{array}{l}\text { Casa da Entrevistada. } \\
\text { Porto Alegre/RS. }\end{array}$ & $\begin{array}{l}1 \mathrm{~h} \mathrm{17min} \\
58 \mathrm{~s}\end{array}$ & 21 \\
\hline $\begin{array}{l}\text { POISL, } \\
\text { Walter }\end{array}$ & $\begin{array}{l}\text { Ex-professor } \\
\text { da instituição }\end{array}$ & $16 / 05 / 2016$ & $\begin{array}{l}\text { Casa do Entrevistado. } \\
\text { Porto Alegre/RS. }\end{array}$ & $\begin{array}{l}\text { h } 31 \mathrm{~min} \\
54 \mathrm{~s}\end{array}$ & 21 \\
\hline
\end{tabular}

Fonte: Elaborado pelos autores (2019)

Como se observa no Quadro 1, foram realizadas quatro entrevistas. Uma delas com a filha de Sven Robert Schulze, Ingrid Schulze; duas com sujeitos que foram colegas de trabalho do professor 
Schulze e; uma com filho de um colega já falecido. Dentre as entrevistas com os antigos colegas de trabalho encontra-se a que foi realizada com o professor Hans Joachim Walter Sille ${ }^{10}$ e com o professor Walter Poisl. Além disso, entrevistou-se Ivam Kley, filho de Walter Kley, professor já falecido. De forma geral, as entrevistas produzidas resultaram em um total de $6 \mathrm{~h} 40 \mathrm{~min} 54 \mathrm{~s}$ de duração e 127 páginas, salvaguardados no acerco pessoal dos autores.

É importante destacar que todos os sujeitos entrevistados conviveram de forma direta com Sven, seja no lugar de colega de trabalho (Hans Walter Sille e Walter Poisl), como filho de um colega e amigo (Ivam Kley) ou, como filha (Ingrid Schultz). Com isso queremos destacar as memórias produzidas nas entrevistas de História Oral estão diretamente ligadas ao tipo de relação existente entre os entrevistados e o biografado, não há portanto neutralidade nas narrativas. Suas memórias são permeadas por sentimentos em relação ao vivido com o personagem e também com sua ausência. É sabido que as memórias são atravessadas por emoções, silenciamentos e esquecimentos. Ao lembrar da vida de um ente ou amigo querido, esses sentimentos afloram e se incorporam a narrativa de memória. Como coloca Portelli (2016), a história oral é uma relação dialógica e recheada de situações singulares, de modo que cabe ao historiador produzir estímulos ao seu entrevistado e explorar tais lembranças.

Por fim, o último grupo de documentos utilizados pode ser genericamente denominado de 'documentos diversos', sendo composto por todas as fontes cedidas pelos sujeitos entrevistados, como fotografias, discursos de formatura, correspondências, entre outros.

\section{SVEN ROBERT SCHULZE: CONTADOR, EMPRESÁRIO E CONSELHEIRO}

No dia 15 de dezembro de 1910, na cidade de Porto Alegre, capital do estado do Rio Grande do Sul, nasceu Sven Robert Schulze, filho de Bernhard Oscar Schulze e Herminia Ida Brandt Schulze ${ }^{11}$. Quem se tornaria este indivíduo? Quais os caminhos seriam percorridos por ele? Como afirma Avelar (2010), as respostas a estes questionamentos não podem ser compreendidas como predestinação, como resultado do destino, uma vez que o enredo de uma vida não é uma trajetória reta em direção a um fim determinado que se manifesta desde a infância.

Assim como a vida de qualquer outro personagem, a de Sven não seria marcada por regularidades, repetições e permanências (AVELAR, 2010). No entanto, ao apresentar uma reconstrução possível da trajetória do nosso biografado, tomamos alguns episódios específicos que nos auxiliam a compreender quem foi este indivíduo e sua contribuição para a formação de técnicos contabilistas na cidade de Porto Alegre. Dessa forma, é para a trajetória escolar, profissional e familiar de Sven que procuramos atentar e nos aproximar.

\footnotetext{
10 O professor Sille faleceu um ano após conceder a entrevista.

11 Informações Retiradas do Livro de Têrmos de Investidura de Professores da ETC. № 1. Disponível no Memorial do Colégio Farroupilha de Porto Alegre - RS.
}

Reflexão e Ação [ISSN 1982-9949]. Santa Cruz do Sul, v. 27, n. 3, p. 109-127, set./dez. 2019.https://online.unisc.br/seer/index.php/reflex/index 
Sobre a trajetória escolar de Sven, podemos destacar que ela foi percorrida pelos caminhos da contabilidade. Portador de dois diplomas, um em nível técnico e outro em nível superior, formou-se no ano de 1936 como perito-contador na Escola Técnica de Comércio de Porto Alegre ${ }^{12}$ e, posteriormente, como Bacharel em Ciências Econômicas pela Faculdade de Ciências Políticas e Econômicas de Porto Alegre ${ }^{13}$. Quando concluiu o curso técnico, no ano de 1936, Sven obteve o seu diploma em um momento particularmente importante da história do ensino comercial brasileiro, uma vez que no ano de 1931 que a profissão de contador havia sido reconhecida ${ }^{14}$. Na sequência, apresentamos uma fotografia do biografado:

Imagem 1: Fotografia ${ }^{15}$ de Sven Robert Schulze

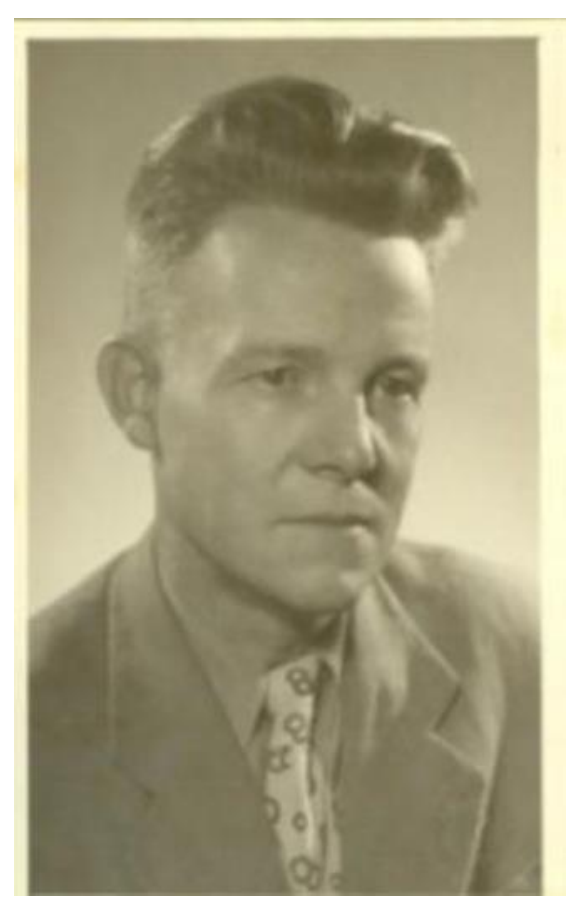

Fonte: Silva (2017)

\footnotetext{
12 Um estudo específico sobre a história da instituição é feito por Vizentini (197). Ao analisar a história da escola, o autor propõe uma periodização em quatro fases: "Da criação à Integração à Universidade de Porto Alegre (1909-1934)", "Da Universidade de Porto Alegre à UFRGS (1934-1950)"; "Da Federalização à Autonomia (1950-1970)”; "Da Autonomia aos dias atuais (1970-1979)". ${ }^{13}$ Livro de Têrmos de Investidura de Professores da ETC. № 1.

14 Assinado por Francisco Campos, o decreto n² 20.158 de 1931 organizou o ensino comercial no Brasil, regulamentou a profissão de contador no país e deu providências específicas sobre a fiscalização desta modalidade de ensino. Composto por três capítulos e 82 artigos, o decreto estabeleceu que o curso comercial seria composto por duas partes: uma de caráter propedêutica e a outra específica da habilitação escolhida (secretariado, guarda-livros, administrador-vendedor, atuário ou peritocontador). Considerando o decreto, podemos inferir que Sven fez o curso propedêutico acrescido da habilitação de peritocontador.

15 A imagem mede $10 \times 15 \mathrm{~cm}$, em papel, em preto e branco.
} 
Na Imagem 1, vemos uma fotografia de Sven. Conforme podemos observar, trata-se de uma fotografia posada, na qual observamos o indivíduo levemente de perfil, vestindo terno e gravata.

Formado no curso técnico comercial com a habilitação de perito-contador, Sven Schulze atuou profissionalmente em diferentes espaços, sobrepondo atividades e exercendo diferentes papeis: era proprietário de uma microempresa e de uma oficina mecanográfica; conselheiro da Associação Beneficente e Educacional (ABE), mantenedora do Colégio Farroupilha; professor e diretor da Escola Técnica de Comércio Farroupilha. Sobre a empresa de Sven, as memórias de sua filha Ingrid Schulze (2016, p.4) apontam que era "[...] uma microempresa que vendia esse tipo de máquinas e tinha uma oficina, então ele era, estava dentro da área também, da mecanografia". Conforme a entrevistada, a empresa de seu pai vendia máquinas ligadas ao ofício da contabilidade, como mimeógrafos, máquinas de escrever, máquinas de calcular, entre outras. Além de sua empresa, Sven atuou também na Associação Beneficente e Educacional (ABE), mantenedora do Colégio Farroupilha de Porto Alegre ${ }^{16}$.

\section{SVEN ROBERT SCHULZE: IDEALIZADOR, DIRETOR E ORGANIZADOR DA ESCOLA TÉCNICA DE COMÉRCIO DO COLÉGIO FARROUPILHA}

É como conselheiro da ABE que Sven pode ser considerado idealizador e criador de uma escola comercial na capital do Rio Grande do Sul. De acordo com um "Demonstrativo da Receita e Despesa da Associação Beneficente e Educacional de 1858"17, em meio ao lamento pela impossibilidade de abertura de um curso colegial complementar ou ginasial na escola, surge a felicitação pela possibilidade de criação de um curso noturno:

\footnotetext{
Mas, em compensação, transmito aos srs. Associados a boa nova de que, por iniciativa do nosso companheiro do Conselho Escolar, dr. Sven Schulze, se cogita da instalação de um curso técnico comercial de contabilidade, à noite. Os estudos em torno da viabilidade de abertura deste curso estão em andamento, mas nem por isso ficou abandonada a ideia de instalação, quanto antes, do curso colegial (ABE, 1949, p. 3).
}

De acordo com o documento, em 7 de abril de $1949^{18}$ já cogitava-se a abertura de um curso técnico comercial em contabilidade, que funcionaria à noite, sendo sua idealização atribuída ao conselheiro escolar, Sven Robert Schulze. A iniciativa de Sven parece ter gerado frutos, pois no final do mesmo ano, anuncia-se a criação da escola, e o conselheiro passa a ser diretor da mesma: "Em 10 de novembro a diretoria elege o diretor da Escola Técnica de Comércio Farroupilha, o Dr. Sven Robert Schulze, que fora o propugnador da ideia, que ora se concretizava. [...] A nova escola passaria a

\footnotetext{
16 Segundo Jacques (2013), a ABE pode ser caracterizada como uma entidade filantrópica, criada no ano de 1858, com o nome de Deutscher Hilfsverein, que significa Sociedade Beneficente Alemã. A autora afirma que as atividades educacionais da associação iniciaram, com a fundação da Knabenschuledes Deutschen Hilfsverein, uma escola para meninos fundada no ano de 1886.

17 O documento consiste em um relatório da diretoria da Associação apresentado pelo seu presidente, Sr. Carlos Tannhauser, em 7 de abril de 1949 .

18 De acordo com Silva (2017), esse período é marcado pelo aumento significativo do número de empresas públicas e privadas na cidade de Porto Alegre/RS, o que justifica a necessidade de profissionais habilitados em contabilidade.
}

Reflexão e Ação [ISSN 1982-9949]. Santa Cruz do Sul, v. 27, n. 3, p. 109-127, set./dez. 2019.https://online.unisc.br/seer/index.php/reflex/index 
funcionar a partir de 1950" (TELLES, 1974, p. 150). Quanto ao cargo de diretor da instituição, cabe ressaltar que Sven o exerceu no período de 1950 a 1953, passando depois ao cargo de vice-diretor. Em paralelo ao cargo administrativo, Sven exerceu também a função de professor.

Depois de criada a escola comercial, cabia contratar os professores que iriam lecionar na instituição. Como se deu este processo? Esta é uma pergunta cujas memórias produzidas com as entrevistas de História Oral permitiram responder.

Ao serem indagados sobre este processo de seleção dos professores, todos os sujeitos entrevistados oferecem respostas que convergem. Sobre a origem da escola e o processo de formação do corpo docente, Ingrid Schulze (2016, p.3) afirma:

Havia uma, digamos assim, uma necessidade de formação profissional de contadores, técnicos em contabilidade. E, aí o pai achou por bem movimentar para criar uma escola desse tipo. [...] Então ele contatou, ele tinha muitos relacionamentos, ele contatou profissionais, de diferentes áreas que compunham aquelas disciplinas necessárias para a formação de um contador, e os conhecidos convidaram outros, então eles formaram uma equipe, eles eram muito amigos e conheciam-se mutuamente, então eles formaram essa escola.

Ingrid afirma que a criação da escola é fruto da necessidade de formação de profissionais para atuarem no comércio, necessidade esta identificada pelo seu pai Sven. Depois de organizar a criação da instituição, Ingrid destaca que seu pai iniciou o processo de composição do corpo docente. O processo de contratação se deu, de acordo com a entrevista, a partir do convite feito por Sven a profissionais que exerciam profissão relacionada às disciplinas necessárias para a composição do currículo do curso. Mais uma vez podemos identificar o papel central exercido por Sven na instituição, em um movimento no qual se cruzam esferas profissionais (escola) e pessoais (amigos convidados para lecionar).

Esta articulação entre as esferas pública e privada pode ser identificada também nas memórias de Walter Kley (2016, p. 7). Ao falar sobre a ideia de criação da escola, afirma: "A ideia, a ideia, isso aí é uma ideia que eles tiveram, essa turminha dele, o, o, o Schultze, [...]. É, eu acho que eles sentiram a necessidade, sentiram a falta de gente especializada e a necessidade de formar gente. Aí que veio, começaram a bolar esse negócio da Escola Técnica". Como podemos observar nas memórias do entrevistado, a ideia de criação também é atribuída ao professor Schultze e a "turminha dele", o que nos permite aferir que o professor contatou conhecidos para compor o corpo docente do curso comercial.

Nesse caso, como outros já identificados em pesquisas de cunho biográfico, a influência pessoal e a circulação em determinadas esferas sociais configuram modos de agir que possibilitam, independentes das políticas públicas, a construção, instauração e organização de determinados setores da educação.

\section{SVEN ROBERT SCHULZE: PROFESSOR}


Apesar dos cargos administrativos, Sven não deixou de lado a profissão docente, exercendo ambas as atividades em paralelo. Atuou como professor entre os anos de 1950 e 1969, completando 19 anos de docência na ETC Farroupilha. Ao longo deste período como profesor, lecionou as disciplinas de Mecanografia, Merceologia, Elementos de Estatística e Técnica Mecanográfica. É interessante observar que as disciplinas ministradas por Sven estão ligadas às máquinas de trabalho dos contadores, o que justifica-se, conforme anteriormente mencionado, pelo fato de possuir uma microempresa e uma oficina na qual trabalhava com tais equipamentos.

Pensando na formação e no exercício da docência, uma pergunta que se interpõe é: como foram as aulas ministradas por Sven? Conforme destacamos anteriormente, os professores da ETC não eram professores de formação, e sim profissionais ligados às disciplinas que compunham o curso comercial, como no caso do próprio Sven. Dessa forma, não é de estranhar que, no exercício da docência, tendesse a valorizar o caráter técnico do ensino. Ao ser indagada se seu pai gostava de exercer a profissão docente e sobre o funcionamento das aulas por ele ministradas, Ingrid Schulze $(2016$, p. 6) afirma:

\footnotetext{
Ele gostava, ele gostava, agora quando a gente conversava com ele, dava para perceber que ele não tinha assim muita pedagogia, ele era assim mais do técnico, muito exato assim né. Então, às vezes, eu imagino que algumas aulas dele tenham sido assim um pouco secas, mas os alunos se adaptavam $[\ldots]$.
}

As memórias da entrevistada evidenciam que Sven gostava de atuar como professor, embora em alguns momentos não tivesse 'muita pedagogia', que pode ser, no contexto da narrativa, entendido como didática para o ensino. Além disso, as memórias da entrevistada evidenciam ainda que suas aulas tendiam a valorizar o aspecto técnico do ensino, que nas disciplinas ministradas, pode ser entendido como a prática de manuseio das máquinas contábeis.

Apesar de aulas 'um pouco secas', o professor Sven parece ter marcado a trajetória de alguns dos alunos que passaram pela Escola Técnica. Quando analisamos os convites de formatura da ETC ${ }^{19}$ observamos que o professor foi homenageado nas formaturas dos anos de 1955, 1956, 1957, 1963 e 1964, o que indica um sentimento de gratidão dos alunos que estavam no final do curso.

Em outros anos, mesmo que não fosse homenageado, o professor Sven encontrava-se presente na cerimônia de final de curso, entregando prêmios ou honrarias. Um destes momentos foi registrado e permanece salvaguardado nas memórias pessoais da filha do professor, podendo ser observado a seguir:

\footnotetext{
19 Os convites de formatura encontram-se salvaguardados no Memorial do Colégio Farroupilha de Porto Alegre - RS, divididos em envelopes por década.
}

Reflexão e Ação [ISSN 1982-9949]. Santa Cruz do Sul, v. 27, n. 3, p. 109-127, set./dez. 2019.https://online.unisc.br/seer/index.php/reflex/index 
Imagem 220: Entrega do prêmio de 'Melhor Colega' pelo professor Sven Robert Schulze, 1960

Fonte: Acervo pessoal de Ingrid Schulze 21

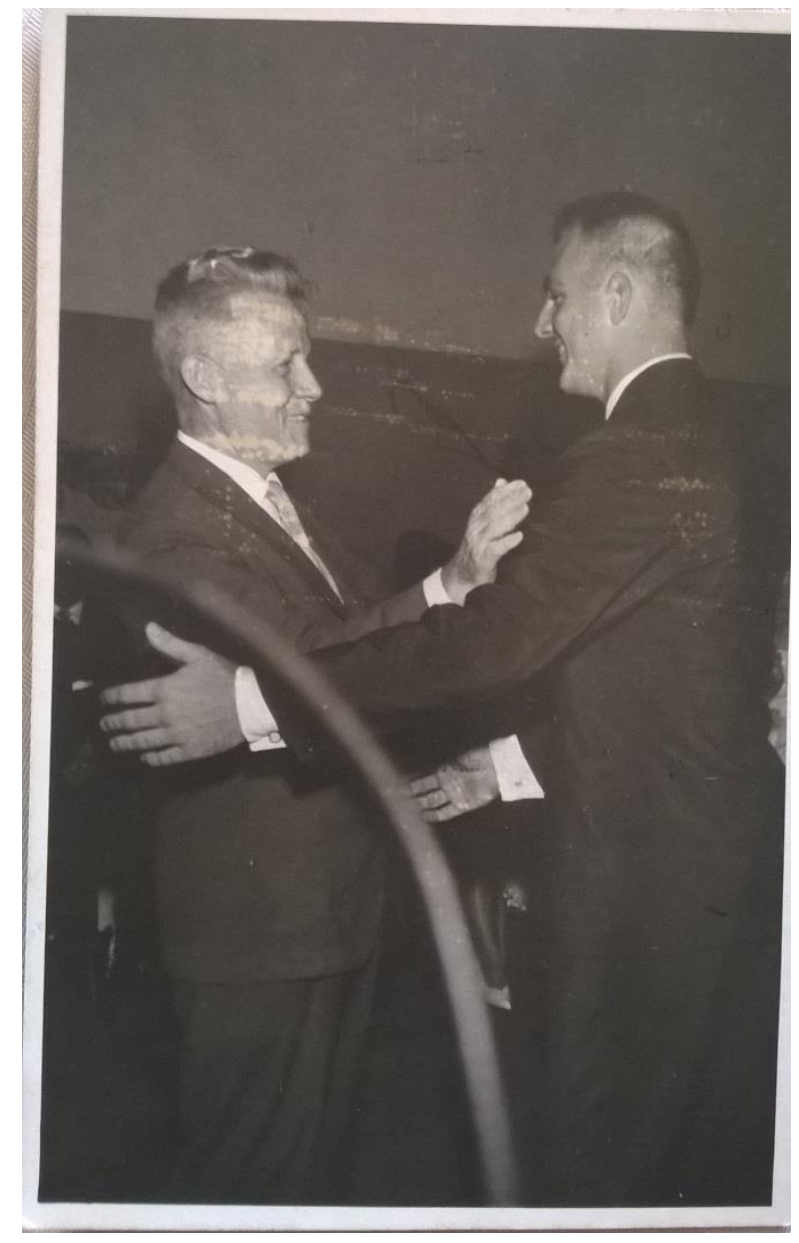

Podemos observar na Imagem 2 o professor Sven (à esquerda) entregando o prêmio de 'Melhor Colega' ao aluno Luiz Henrique Kramer (à direita), formando da $9^{a}$ turma do curso técnico em contabilidade. A foto posada apresenta aluno e professor, cujo traje e gesto de cumprimento revelam se tratar de um momento importante, evidenciando o caráter simbólico do ritual de formatura.

Além do momento registrado pela fotografia anterior, no qual Sven encontra-se em evidencia com um dos alunos formandos da ETC, cabe destacar também o registro de Sven com os demais colegas, que pode ser observado na imagem que segue:

\footnotetext{
20 Fotografia em preto e branco, medindo $10 \times 15 \mathrm{~cm}$.

${ }^{21}$ Cabe destacar que foram tomados os cuidados éticos em relação a construção da biografia, com total respeito e cuidado em relação ao biografado e a seus familiares, sem jamais encararmos a vida de Sven como um objeto (AVELAR, 2010). Dessa forma, a imagem guardada por Ingrid somente foi divulgada a partir do consentimento por termo livre esclarecido da mesma.
} 
Imagem 322: Professores da Escola Técnica de Comércio do Colégio Farroupilha

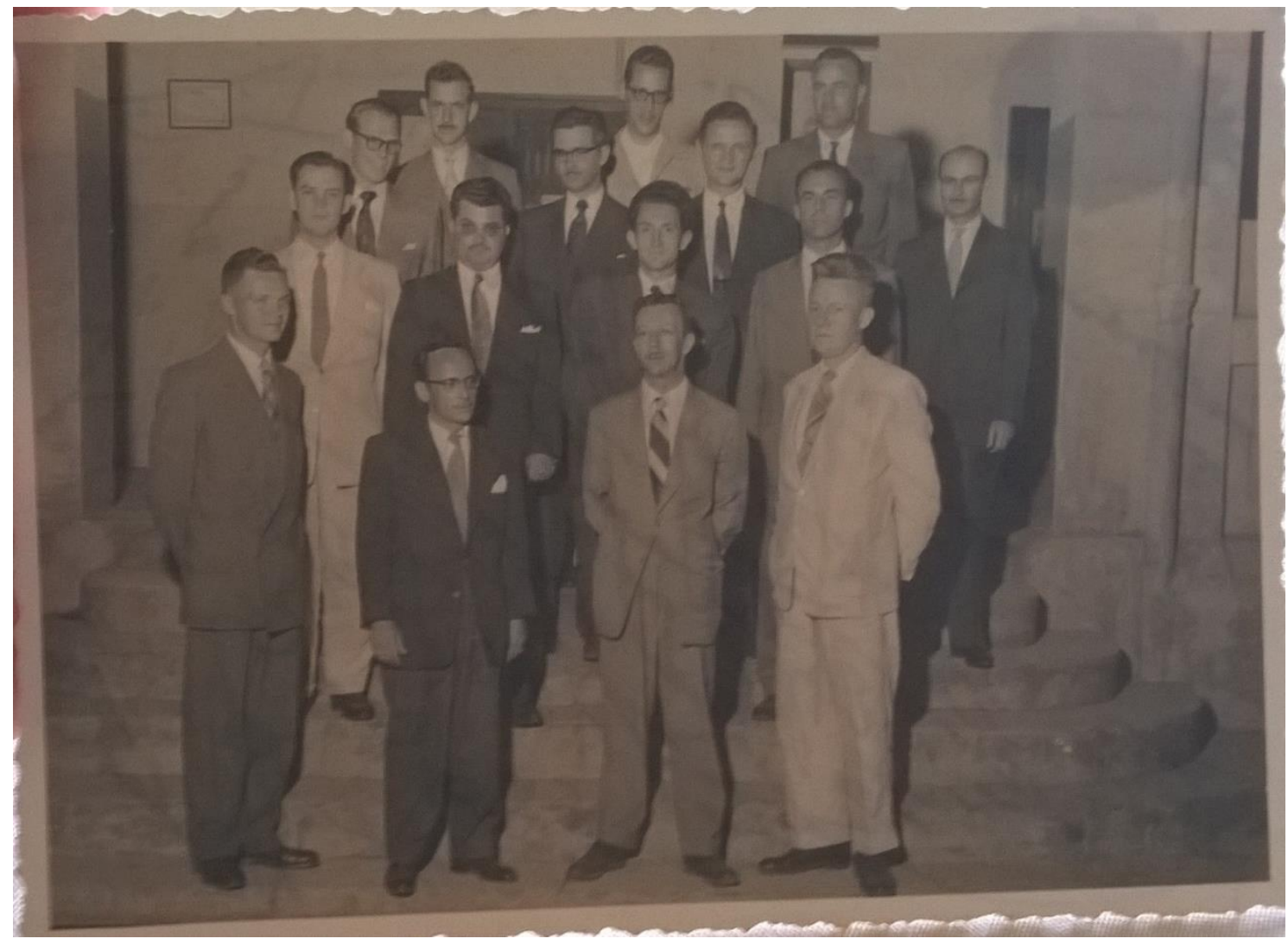

Fonte: Acervo pessoal de Ingrid Schulze

$\mathrm{Na}$ imagem 3 podemos observar o corpo docente da ETC Farroupilha. Diferentemente da foto anterior que possuía registro no verso, esta imagem não conta com maiores informações. No entanto, o cruzamento com demais documentos permite algumas informações. Inicialmente, é provável que a foto date da década de 1950, uma vez que até este momento o corpo docente era composto apenas por homens ${ }^{23}$.

Quanto aos sujeitos na fotografia, no primeiro plano, da esquerda para a direita, é possível afirmar que o primeiro deles é o professor Hans Joachim Walter Sille, o terceiro o professor Walter Kley, seguido de nosso biografado professor Sven. No segundo nível, o segundo sujeito da esquerda para a direita provavelmente é o professor Casimiro Medeiros Jacobs, sucedido pelo professor Walter Jacob Striebel. No terceiro plano, o segundo sujeito da esquerda para a direita é o professor Walter Egon Poisl e, para finalizar, é provável que o primeiro indivíduo da esquerda para a direita, no último plano, seja o professor Ely Fumagalli Horta.

\footnotetext{
${ }^{22}$ Fotografia em preto e branco, medindo $10 \times 15 \mathrm{~cm}$.

${ }^{23}$ A primeira mulher contratada como professora da ETC Farroupilha foi Lélis Souza de Souza. Embora ministrasse aulas na condição de professora provisória desde 1958, Lélis foi contratada apenas em 1962 como parte oficial do corpo docente da instituição. Uma vez que a escola foi fundada em 1950 e que a contratação da professora ocorreu em 1958, observa-se que nos oito primeiros anos de existência da instituição o quadro de professores era formado apenas por homens (SILVA, 2017).
}

Reflexão e Ação [ISSN 1982-9949]. Santa Cruz do Sul, v. 27, n. 3, p. 109-127, set./dez. 2019.https://online.unisc.br/seer/index.php/reflex/index 


\section{SVEN ROBERT SCHULZE: COTIDIANO DOMICILIAR}

Nesta seção, abordaremos alguns elementos que compõe a vida privada de nosso personagem. Casado, o professor Sven foi pai de cinco filhos, sendo quatro homens (Edgar Schulze, Udo Schulze, Martin Schulze, Ingo Edgar Schulze) e uma mulher (Ingrid Schulze). Parte significativa das informações sobre Sven foram produzidas a partir das memórias de sua filha, Ingrid. Entre lembranças e esquecimentos características da Memória (RICOEUR, 2007), a entrevistada narrou emocionada, não apenas elementos da vida de seu pai, mas de um profissional pelo qual tivera grande admiração. Pai, contador, professor e empresário misturavam-se na fala emocionada de sua filha.

Dos 5 filhos do professor Sven, cabe destacar que três seguiram a mesma carreira profissional do pai, formando-se não apenas técnicos em contabilidade, mas tendo estudado na instituição idealizada por Sven. No ano de 1967 o primeiro filho formava-se técnico em contabilidade, Edgard Schulze. No ano seguinte, em 1968, o segundo filho ganhara o diploma da ETC, Udo Schulze. No ano de 1970, um ano após o professor Sven deixar de lecionar no curso comercial, forma-se contador Martin Schulze, o terceiro filho a seguir a formação do pai24. O que levou os filhos do Professor a realizarem o mesmo curso que o pai, inclusive na instituição por ele idealizada?

Ingrid Schulze evidencia que essas escolhas não foram obra do destino, mas do próprio núcleo familiar ou também obras do acaso. Ao rememorar os motivos que levaram seus irmãos a cursarem à ETC Farroupilha, Ingrid (2016, p.5) afirma que "naquela época os cursos técnicos eram bem fortes. Você faz um curso técnico, você termina o curso técnico, tem diploma, estabilidade, vai seguir uma profissão. Ta feito. E se quiser, segue uma universidade, mas essa base tu já tens, não vai ficar ao leo".

Na mesma época, estudos sobre as profissões para mulheres, a mesma lógica é empregada: moças deveriam fazer o curso normal, assim, se não casassem teriam uma profissão e garantiriam seu sustento (GRAZZIOTIN, 2008).

De acordo com as memórias de Ingrid, as escolhas dos irmãos em cursar o ensino técnico referem-se à ideia de estabilidade que esta modalidade de ensino oferecia naquele momento, porque o diploma de um curso técnico permitia iniciar uma profissão. Sobre a escolha pelo técnico em contabilidade, a entrevistada, especificamente, ressalta o motivo desta escolha: "Ele [o pai, Sven] gostaria que alguém assumisse a empresa que ele tinha né, [...]" (INGRID, 2015, p. 18). É importante destacar que, embora não tenham cursado o técnico em contabilidade, os outros dois filhos do professor Sven também fizeram cursos técnicos, sendo que Ingo Edgar Schulze fez o curso Técnico Agrícola e Ingrid Schulze o curso técnico em artes aplicadas.

Cabe ainda, para finalizar, destacar a importância de Ingrid Schulze para a realização deste trabalho, importância esta que nos permite entende-la como uma "guardiã da memória25", porque

\footnotetext{
24 Informações retiradas do Mapa de Contribuições de 1970, salvaguardado no Memorial do Colégio Farroupilha.

25 O termo é empregado por Angela de Castro Gomes (1996) ao analisar entrevistas cedidas por Alzira Vargas do Amaral Peixoto, filha de Getúlio Vargas, uma vez que ela guardou diferentes documentos do pai, bem como pode ter uma 'visão de dentro' da política do país devido a relação familiar com o presidente.
} 
como filha do idealizador, primeiro diretor e professor da ETC Farroupilha, vivenciou inúmeras atividades da escola, esteve presente em formaturas, reuniões e encontros, bem como preservou uma série de documentos como fotografias, notícias de jornais, entre outros, que funcionaram como dispositivos desencadeadores de memórias durante a entrevista e, ao mesmo tempo, foram utilizados na construção deste texto.

\section{APONTAMENTOS FINAIS}

A partir da análise de uma variada gama de fontes, identificamos elementos da vida de Sven Robert Schulze que nos permitiram compor essa narrativa sobre alguns aspectos de sua vida. Inicialmente, destacamos a formação de Sven voltada para a contabilidade, o que permitiu-lhe trabalhar como contador, empresário (proprietário de uma microempresa e de uma oficina mecanográfica) e, ao mesmo tempo, conselheiro da associação ( $A B E)$ mantenedora do Colégio Farroupilha de Porto Alegre.

Essa trajetória foi marcada, nos anos 1950 pela idealização de um Curso Comercial o Colégio Farroupilha, resultando na criação da Escola Técnica de Comércio, instituição que formou técnicos em contabilidade entre os anos de 1950 e 1983. Além de idealizar esta instituição, Sven atuou ainda como diretor e como professor de disciplinas voltadas para seu campo de trabalho.

Chervel (1990, pg. 177) faz o seguinte questionamento "[...] a observação histórica permite resgatar as regras de funcionamento, ver um ou vários modelos disciplinares ideais, cujo conhecimento e exploração poderiam ser de alguma utilidade nos debates pedagógicos atuais ou do futuro?" Pelas próprias discussões de Chervel (1990), nesse estudo e em outros por nós realizados, acreditamos que sim. Ao dimensionar alguns aspectos da vida do professor Sven sob o ponto de vista do gênero biográfico ${ }^{26}$ nos deparamos com alguns aspectos em nível micro - Colégio Farroupilha de Porto Alegre - que nos remete ao percurso de criação e implementação do ensino técnico comercial no Brasil ${ }^{27}$. Os desdobramentos desse processo permitem uma reflexão sobre as políticas públicas e as relações de poder vinculadas ao ensino profissional no Brasil como um todo e, sobre o Ensino comercial e as disciplinas que o compõe, de forma particular. A dimensão histórica de uma pesquisa produz a possibilidade de compreensão das racionalidades presentes em cada época e em alguma medida, a prospecção de situações futuras, "um futuro em devir" (KOSELLECK, 2006, p. 159)

Assim, as memórias sobre ele remetem ao exercício de diferentes cargos naquele espaço e a postura adotada diante dos mesmos. As distintas nuances que compõe a vida do personagem em questão, emergem com lembranças e se integram na composição da trajetória de idealizador da Escola da qual se tornou diretor e cuja prática docente sempre fora mantida mesmo com as demais atividades. Um empresário que gostava se ser professor, que gostava de lecionar, embora não tivesse "muita pedagogia".

\footnotetext{
26 Para saber sobre a elação gênero biográfico e educação ver a pesquisa de Ariane dos Reis Duarte (2018).

${ }^{27}$ Sobre o processo de emergência, afirmação as transformações do Ensino Comercial no Brasil, ver o trabalho de Silva (2018).
} 
Com isso, observamos que algumas dimensões de sua existência estão diretamente atreladas à ETC Farroupilha e, cuja relação com a instituição transcende a vida profissional, de modo que "O Farroupilha" faz parte da vida e da formação dos descendentes do professor Sven Schulze. Nesse sentido, as lembranças do Ingrid Schulze sobre a atuação do pai na instituição são permeadas por elementos que mesclam sua afeição a ambos.

Por fim, consideramos que o ensaio biográfico aqui construído, contribui, em certa medida, para uma reflexão sobre a História da Educação Brasileira, sobretudo no que diz respeito a participação do indivíduo e suas singularidades nesse contexto.

\section{REFERÊNCIAS}

1. AVELAR, Alexandre de Sá. 2010. A Biografia como escrita da História: possibilidades, limites e tensões. Dimensões, v. 24. 2010. ISSN 2179-8869. Disponível em: < http://www.periodicos.ufes.br/dimensoes/article/view/2528>. Acesso em: 05/06/2019.

2. BASTOS, Maria Helena Camara. O que é História da Educação hoje? Tempos de Reflexão. Espacio, Tiempo y Educación, v.3, n.1, jan.-jul. 2016. ISSSN 2340-7263. Acesso em: 05/06/2019. doi: http://dx.doi.org/10.14516/ete.2016.003.001.4.

3. CHARTIER, Roger. A História Cultural entre práticas e representações. Rio de Janeiro: Bertrand Brasil, 1990.

4. CHERVEL, André. História das Disciplinas Escolares: reflexões sobre um campo de pesquisa. Revista Teoria e Educação, Porto Alegre, v.2. 1990. Disponível em: <https://moodle.fct.unl.pt/pluginfile.php/122510/mod_resource/content/0/Leituras/Chervel01.pdf>. Acesso em: 05/06/2019.

5. DEL PRIORE, Mary. Biografia: quando o indivíduo encontra a história. Topoi, Rio de Janeiro, v. 10, n. 19, jul.-dez. 2009. ISSN 1518-3319. Disponível em: < http://www.scielo.br/pdf/topoi/v10n19/2237101X-topoi-10-19-00007.pdf>. Acesso em: 05/06/2019. doi: http://dx.doi.org/10.1590/2237$101 \times 010019001$.

6. DOSSE, François. A História. São Paulo: UNESP, 2012.

7. DOSSE, François. O desafio biográfico: escrever uma vida. São Paulo: Universidade de São Paulo, 2015. 
8. DUARTE, Ariane dos Reis. "O homem que fez 2000 escolas": representações sobre Felipe Tiago Gomes e seu percurso frente à Campanha Nacional da Escola da Comunidade - CNEC (19402000). 2018. 177 f. Tese (Doutorado em Educação) - Universidade do Vale do Rio dos Sinos, São Leopoldo.

9. GRAZZIOTIN, Luciane. Sgarbi; ALMEIDA, Dóris. Bitencourt. Romagem do tempo e recantos da memória: reflexões metodológicas sobre História Oral. São Leopoldo: Oikos, 2012.

GRAZZIOTIN, Luciane Sgarbi. Memórias recompondo tempos e espaços da educação - Bom Jesus/RS (1913-1963). 2008. 379 f. Tese (Doutorado em Educação) - PUCRS, São Leopoldo.

11. JACQUES, Alice Rigoni; GRIMALDI, Lucas Costa. O Memorial do Deutscher Hilfsverein ao Colégio Farroupilha: Um Espaço de Ensino e Pesquisa (2002). In: BASTOS, Maria Helena Camara. et al. (Org.). Do Deutscher Hilfsverein ao Colégio Farroupilha/RS: memórias e histórias (1858-2008). Porto Alegre: EDIPUCRS, 2013.

12. JACQUES, Alice Rigoni. Associação Beneficente Educacional de 1858 e o Colégio Farroupilha (1886). In: BASTOS, Maria Helena Camara. et al. (Org.). Do Deutscher Hilfsverein ao Colégio Farroupilha/RS: memórias e histórias (1858-2008). Porto Alegre: EDIPUCRS, 2013.

13. KLEY, Ivam. Entrevista sobre a Escola Técnica Comercial do Colégio Farroupilha de Porto Alegre [28/01/2016]. Entrevistador: Eduardo Cristiano Hass da Silva, 2016.

14. LE GOFF, Jacques. São Luís - Biografia. Rio de Janeiro: Record, 1999.

15. Le GOFF, Jacques. São Francisco de Assis. Rio de Janeiro, Record, 2011. LORIGA, Sabina. O pequeno x: da biografia à história. Belo Horizonte: Autêntica Editora, 2011.

17. KOSELLECK, Reinhart. Futuro passado: contribuição a semântica dos tempos históricos. Rio de Janeiro, Ed PUC Rio, 2006.

18. MAUAD, Ana Maria. Através da Imagem: fotografia e história interfaces. Tempo. Rio de Janeiro, v. 1, n. 2. 1996. Disponível em: <http://www.historia.uff.br/tempo/artigos_dossie/artg2-4.pdf> Acesso: 08/05/2015.

19. POISL, Walter. Entrevista sobre a Escola Técnica Comercial do Colégio Farroupilha de Porto Alegre [16/05/2016]. Entrevistador: Eduardo Cristiano Hass da Silva, 2016.

20. PORTELLI, Alessandro. História oral como arte da escuta. São Paulo: Letra e Voz, 2016. 
21. RICOEUR, Paul. A Memória, a história, o esquecimento. Campinas: Editora da Unicamp, 2007. SCHULTZ, Ingrid. Entrevista sobre a Escola Técnica Comercial do Colégio Farroupilha de Porto Alegre [29/01/2016]. Entrevistador: Eduardo Cristiano Hass da Silva, 2016.

SILLE, Hans Joachim Walter. Entrevista sobre a Escola Técnica Comercial do Colégio Farroupilha de Porto Alegre [11/12/2015]. Entrevistadores: Eduardo Cristiano Hass da Silva e Lucas Costa Grimaldi, 2015.

SILVA, Eduardo Cristiano Hass. A Gênese de um Espaço Profissional: A Escola Técnica de Comércio do Colégio Farroupilha de Porto Alegre/RS (1950-1983). 2017. 289 f. Dissertação (Mestrado em História) - Pontifícia Universidade Católica do Rio Grande do Sul, São Leopoldo.

SILVA, Eduardo Cristiano Hass da. O ENSINO COMERCIAL NO BRASIL (SÉCULO XIX e XX): emergência, afirmação e processos de transformação. 2018. 151 f. Projeto de qualificação (Tese de doutorado em Educação) - Universidade do Vale do Rio dos Sinos, São Leopoldo.

STEPHANOU, Maria. BASTOS, Maria Helena Camara. História, memória e História da Educação. In: STEPHANOU, M; BASTOS, M. H. C. (Org.). Histórias e Memórias da Educação no Brasil. VIII Século XX: Vozes, 2005.

27. VIÑAO, Antonio. $2^{\mathrm{a}}$ Ed. Sistemas educativos, culturas escolares y reformas. Morata, 2006.

28. VIZENTINI, Paulo Gilberto Fagundes. Do Curso Geral à Escola Técnica de Comércio 1909-1979: a história do ensino técnico comercial de segundo grau na UFRGS. Porto Alegre, 1979.

\section{Eduardo Cristiano Hass da Silva}

Doutorando em Educação na Universidade do Vale do Rio dos Sinos. Licenciado e Mestre em História pela Pontifícia Universidade Católica do Rio Grande do Sul.

\section{Ariane dos Reis Duarte}

Doutora em Educação pela Universidade do Vale do Rio dos Sinos/UNISINOS. Mestra em Educação, com ênfase em História da Educação pela UNISINOS. Graduada em História pela UNISINOS. 


\section{Luciane Sgarbi Santos Grazziotin}

Possui Pós-doutorado na UNED em Madri, doutorado em Educação, ênfase em História da Educação pela PUCRS. Fez doutorado sanduíche na Universidade Clássica de Lisboa. Fez Mestrado em Ciências e graduação em Biologia Licenciatura.

\section{Como citar este documento:}

HASS DA SILVA, Eduardo Cristiano; DUARTE, Ariane dos Reis; GRAZZIOTIN, Luciane Sgarbi Santos. Um ensaio biográfico: memórias do professor Sven Robert Schulze. Reflexão e Ação, Santa Cruz do Sul, v. 27, n. 3, p. 109-127, out. 2019. ISSN 1982-9949. Disponível em: <https://online.unisc.br/seer/index.php/reflex/article/view/13630>. Acesso em: doi:https://doi.org/10.17058/rea.v27i3.13630. 